DOI 10.12737/2073-0462-2021-23-28

УДК 633.111.1:631.529

АНАЛИЗ СТРУКТУРЫ УРОЖАЯ ЯРОВОЙ ПШЕНИЦЫ В РАЗЛИЧНЫХ ПОГОДНЫХ УСЛОВИЯХ ТЮМЕНСКОЙ ОБЛАСТИ

Е.С. Земцова, Н.А. Боме

Реферат. Исследования проводили с целью определения особенностей формирования урожайности яровой мягкой пшеницы на основе анализа изменчивости основных элементов ее структуры в условиях таежной агроклиматической зоны Тюменской области. Эксперименты выполняли в 2014-2016 гг. на 22 сортах яровой мягкой пшеницы, относящихся к двум группам спелости (среднеранние и среднеспелые). Площадь делянки - $1 \mathrm{~m}^{2}$, повторность - 4-х кратная. Почва по гранулометрическому составу суглинистая, содержание гумуса $-4,5 \%, \mathrm{pH}=7,1$. Фактором, лимитирующим урожай пшеницы, в первый год исследования была недостаточная теплообеспеченность (среднесуточная температура воздуха на $1,4{ }^{\circ} \mathrm{C}$ ниже среднемноголетней) на фоне дефицита осадков (62\% по отношению к норме), что стало причиной формирования щуплого зерна. Во второй год обильные осадки (155\% к норме за вегетационный период), в июле носившие ливневый характер, привели к полеганию растений и увеличению зараженности зерна грибными болезнями. В третий год высокая температура воздуха (на $3,2^{\circ} \mathrm{C}$ выше среднемноголетней) обусловили сокращение продолжительности фазы кущения и снижение числа продуктивных побегов. Значительной вариации в период исследования были подвержены признаки - число побегов, масса зерна с колоса, масса 1000 зерен и длина стебля (коэффициенты вариации (CV) составили $20 \ldots 22 \%)$, практически не изменялись - число зерен в колосе и длина колоса $(C V-2 \ldots 3 \%)$. Наблюдали компенсацию одних элементов структуры урожая другими. Недостаточное число стеблей компенсировалось увеличением доли продуктивного стеблестоя, низкое число продуктивных побегов - более высокой продуктивностью колоса, относительно низкая озерненность колоса - увеличением массы 1000 зерен. В результате уровень урожайности по годам исследования варьировал незначительно $(C V-7 \%)$.

Ключевые слова: пшеница мягкая яровая (Triticum aestivum L.), сорт, структура урожая, погодные условия, Тюменская область.

Введение. Среди факторов, влияющих на урожайность пшеницы и других зерновых культур, важнейшую роль играют погодные условия. Уже более века происходит глобальное потепление климата $[1,2,3]$, увеличивается частота и интенсивность экстремальных погодных явлений $[4,5]$. Китайскими исследователями для пяти основных странпроизводителей пшеницы установлено, что повышение температуры воздуха на каждый градус Цельсия приводит к потере глобального урожая зерна на $6 \%$ [6]. Эффект потепления зависит от базового климата и географически неоднороден. Считается, что более теплые регионы будут страдать от большей потери урожая при повышении температуры, чем более холодные [7]. Имеются данные, что пшеничные пояса продвигаются к полюсам со скоростью до 160 миль за десятилетие [8]. На фоне мрачных прогнозов изменения климата обеспечение стабильного увеличения урожайности для удовлетворения растущего спроса важная проблема для всего мира.

В Тюменской области яровая пшеница основная продовольственная культура [9]. Ее высевают на площади более 400 тыс. га, средняя урожайность достигает $2,0 \ldots 2,2 \mathrm{~T} / \mathrm{ra}$, в лучших хозяйствах собирают по $4 \ldots . .5$ т/га и более. Доля зернового клина, занятого сортами местной селекции, составляет $60 . .70 \%$ [10]. Зерновые культуры выращивают только в южной части области, которая в агроклиматическом отношении разделена на четыре зоны: таежная, подтаежная, северная лесостепь и южная лесостепь [11]. Лимитирующие факторы возделывания пшеницы в регионе - де-

фицит влаги в первой половине вегетационного периода и, наоборот, избыточное увлажнение с недостатком тепла во второй половине вегетации, часто случаются ранние августовские заморозки, повреждающие недозревшее зерно в колосе $[10,12]$. Отмечают значительную вариабельность основных агрометеорологических параметров по годам и непредсказуемость проявления тех или иных стрессфакторов. Разница температуры воздуха вегетационного периода прохладных лет и лет с повышенным температурным режимом составляет $4 \ldots 5^{\circ} \mathrm{C}$, по количеству осадков во время вегетации влажные и засушливые годы отличаются в $2 . . .5$ раз [13]. В течение последних десятилетий в регионе, как и во всем миpe, наблюдается рост среднегодовой температуры воздуха [13]. Учитывая экстремальные условия земледельческих зон, в Тюменской области нужны хорошо адаптированные сорта, стабильно формирующие урожайность и качество зерна по годам $[13,14]$.

Цель исследований - определение особенностей формирования урожайности сортов яровой мягкой пшеницы на основе анализа изменчивости главных элементов ее структуры в условиях таежной агроклиматической зоны Тюменской области.

Условия, материалы и методы. Работу проводили в 2014-2016 гг. на опытном поле, расположенном в таежной агроклиматической зоне Тюменской области. Изучали сорта яровой мягкой пшеницы среднеранней и среднеспелой групп спелости Омская 36, Казахстанская 10, Икар, Скэнт 3, Авиада, Лютесценс 70, Рикс, Тюменская 25, Тюменская 29, Терция, 
Лютесценс 585, Серебрина, Тюменская 27, Тюменская 33, Тюменская 32, Тюменская 31, Тюменская 30, Тюменец 2, Аделина, Krabat, Laban, CN 06600. Для проведения исследований закладывали микрополевые опыты в четырехкратной повторности. Норма высева 500 семян на $1 \mathrm{~m}^{2}$, ширина междурядья 15 см, глубина заделки семян - 3 см. В первый год исследования для посева использовали семена Селекционно-семеноводческого центра по растениеводству научноисследовательского института сельского хозяйства Северного Зауралья, в последующие годы - семена предыдущего урожая. Учитывали полевую всхожесть семян, число растений, сохранившихся к уборке урожая, общее число побегов и число продуктивных побегов, кустистость, длину стебля и колоса, площадь флагового листа, число колосков в колосе, число зерен в колосе, массу зерна с колоса, массу 1000 зерен, урожайность с 1 м $^{2}$.

Химический анализ пахотного слоя почвы выполняли в химико-экологической лаборатории ТКНС УрО РАН, имеющей государственную аккредитацию, подтверждающую компетентность в проведении аналитических работ. Величину водородного показателя солевой вытяжки из почвы определяли по ГОСТ 26483 -85 , содержание нитратного азота - по ГОСТ 26488-85, подвижного фосфора - по ГОСТ Р 54650-2011, гумуса - по методу И. В. Тюрина. Почва экспериментального участка характеризовалась высокой обеспеченностью нитратным азотом (17,2 $\pm 1,6$ мг/кг), очень высоким содержанием подвижного фосфора $(1154 \pm 4$ мг/кг), средними запасами гумуса в пахотном слое $(4,5 \pm 0,3 \%)$, нейтральной реакцией ( $\mathrm{pH}=7,1 \pm 0,0$ ед.), по гранулометрическому составу классифицировалась как суглинистая.

При характеристике метеорологических условий использовали архив сайта rp5.ru (OOO «Расписание Погоды», г. Санкт-Петербург, лицензия Росгидромета №1691595 Р/2013/2331/100/Л). В годы исследования наблюдали резкие колебания гидротермических факторов. Вегетационный период 2014 г. отличался относительно низкой температурой воздуха, которая в среднем составила $14,4{ }^{0} \mathrm{C}$ (при усредненной величина этого показателя за предшествующие 10 лет $15,8^{0} \mathrm{C}$ ), в 2015 г. средняя температура воздуха составила $15,5^{0} \mathrm{C}$, а в 2016 г. $-19,0{ }^{0}$ С. Соответственно, по годам различалась продолжительность вегетационного периода, так, в среднем для исследованных сортов в 2014 г. она составила 116 дней (сумма среднесуточных температур $\left.1661{ }^{0} \mathrm{C}\right)$, в 2015 г. -114 дней $\left(1768^{\circ} \mathrm{C}\right)$, в 2016 г. -89 дней $\left(1696^{0} \mathrm{C}\right)$. По сравнению со среднемноголетними значениями (в среднем за соответствующий период 2003-2013 гг. 245 мм), в 2014 г. регистрировали небольшое количество осадков в период вегетации растений - 152 мм. В 2015 г. сумма осадков превысила показатели предыдущего года в 2,5 раза и составила 383 мм, в середине вегетационного периода наблюдали сильные ливневые дожди. В 2016 г. общее количество осадков находилось на уровне $251 \mathrm{мм}$, обильные дожди (до 46 мм в сутки) отмечали в фазе выхода растений в трубку.

В качестве описательных статистик использовали среднее значение и стандартное отклонение $(\mathrm{M} \pm \mathrm{SD})$, для сравнения степени изменчивости признаков применяли коэффициент вариации $(C V)$, варьирование считали слабым, если $C V$ не превосходил $10 \%$, средним $-11 \ldots$ $25 \%$, и значительным - больше $25 \%$ (по классификации Г. Ф. Лакина, 1990). Поскольку распределение исследуемых признаков не всегда подчинялось закону нормального распределения, при проверке статистических гипотез использовали непараметрические методы критерий Краскела-Уоллиса и коэффициент ранговой корреляции Спирмена $\left(r_{s}\right)$. Критический уровень статистической значимости $(p)$ принимали равным 0,05. В тексте статьи приведены только статистически значимые значения $r_{s}(p<0,05)$.

Результаты и обсуждение. При норме высева 500 шт./м², среднее число растений на $1 \mathrm{~m}^{2}$ к уборке урожая в первые два года исследования составляло соответственно $357 \pm 37$ и $356 \pm 29$ шт., в третий год $-310 \pm 28$ шт. (рис. 1). Такая ситуация была обусловлена тем, что в 2016 г. для посева использовали семена урожая предыдущего года, для которого были характерны проливные дожди в середине вегетационного периода, что привело к полеганию растений, увеличению зараженности семян болезнями. В результате в третий год полевая всхожесть семян была ниже, чем в два предыдущих (в среднем по сортам 73,1 $\pm 6,0$ \% и $77,9 \ldots 82,8 \%$ соответственно), при относительно невысоких значениях сохраняемости растений $(85,5 \pm 3,8$ \% и 91,9...86,4 \%). Численность растений на единице площади в большей мере определялась полевой всхожестью семян $\left(r_{s}\right.$ между этими признаками в разные годы был равен $0,83,0,76$ и 0,77 соответственно), нежели сохраняемостью растений $\left(r_{s}\right.$ в 2014 г. составил 0,64, в остальные годы не имел статистической значимости).

Общая кустистость растений яровой пшеницы в первые два вегетационных сезона была высокой и составляла соответственно $2,9 \pm 0,3$ и 2,8 $\pm 0,3$ побега на одно растение. В третий год она не компенсировала снижения численности растений, наоборот, наблюдали уменьшение кустистости - в среднем до 2,3 $\pm 0,2$. Известно, что на энергию кущения сильное влияние оказывает продолжительность этой фазы. Высокие температуры воздуха в 2016 г., в том числе в первой трети вегетации растений (больше предыдущих лет на $1,1 \ldots 1,5^{\circ} \mathrm{C}$ ), привели к сокращению длительности фазы кущения и образованию меньшего количества боковых побегов. Таким образом, общее число побегов на $1 \mathrm{~m}^{2}$ в 2016 г. было значительно ниже, чем в 2014 и 2015 гг., и составляло 
СЕ ЛЬСКОХОЗ ЯЙСТВЕННЫЕ НАУКИ

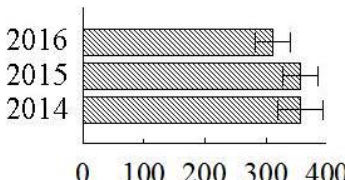

$0 \quad 100200 \quad 300 \quad 400 \quad 0$

Число

растений, шт./ $\mathbf{M}^{2}$

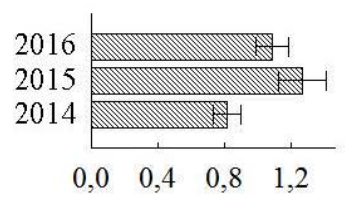

Продуктивность колоса,

$\Gamma$

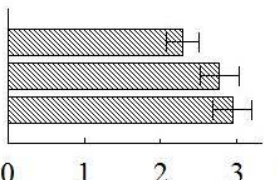

Кустистость, побегов/растение

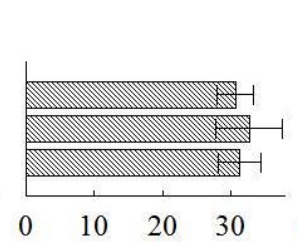

$$
\begin{gathered}
\text { Число зерен } \\
\text { в колосе, }
\end{gathered}
$$

шт.

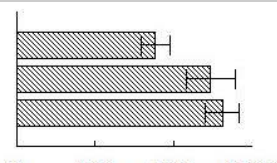

$\begin{array}{lllll}0 & 400 \quad 800 & 1200 & 0\end{array}$

Число

побегов,

шт. $/ \mathrm{M}^{2}$

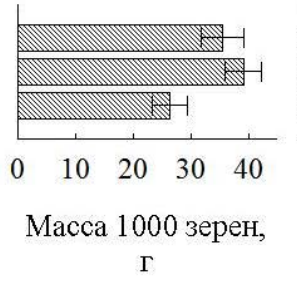

$\Gamma$

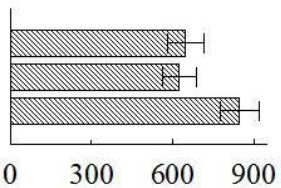

Продуктивный

стеблестой шт. $/ \mathrm{M}^{2}$

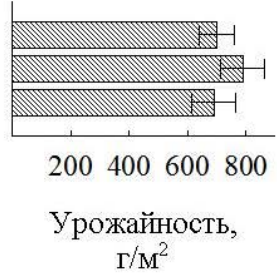

Рис. 1 - Усредненные значения (M, SD) основных элементов структуры урожая яровой пшеницы в разные годы исследования

$705 \pm 74$ шт., против $1047 \pm 86$ и $988 \pm 125$ шт. соответственно. При этом доля продуктивных стеблей в их общем числе в 2016 г. была самой высокой $-91,8 \pm 2,4 \%$, тогда как в 2014 г. она находилась на уровне $81,5 \pm 6,0 \%$, в 2015 г. $-64,6 \pm 7,1 \%$, несмотря на близкие с предыдущим годом показатели общего числа побегов. Продуктивная кустистость по годам исследования составили соответственно 2,4 41,8 , $1,8 \pm 1,5$ и 2,1 $\pm 1,7$ побегов на растение, что выше средних величин этого показателя по Тюменской области - 1,0...1,4 шт. [12].

Размеры урожая во многом зависят от двух элементов - густота продуктивного стеблестоя и продуктивность колоса. Это обобщающие показатели, которые охватывают ряд более мелких параметров. В первый год исследования сформировался наибольший продуктив-

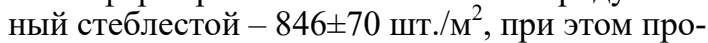
дуктивность колоса была самой низкой 0,82 $\pm 0,08$ г (см. рис. 1). Во второй год, наоборот, регистрировали наименьшую величину продуктивного стеблестоя - 624 163 шт./1 м², а масса зерна с колоса была самой высокой $1,27 \pm 0,14$ г. Таким образом, недостаточное развитие одного элемента урожайности компенсировало усиленное формирование другого, что привело в какой-то мере к стабилизации урожая. Средняя урожайность по годам исследования составила $689 \pm 76$ г/ ${ }^{2}, 787 \pm 75$ г/ $\mathrm{M}^{2}$ и $700 \pm 60$ г/ $\mathrm{M}^{2}$ соответственно. Коэффициент вариации $(C V)$ по годам для числа продуктивных стеблей был равен 17 \% (средняя степень рассеивания данных), массы зерна с колоса $22 \%$ (средняя степень), урожайности - $7 \%$ (незначительная степень). Коэффициенты корреляции урожайности с продуктивным стеблестоем в разные вегетационные периоды находились на уровне $0,50,0,60$ и 0,61 , с массой зерна с колоса в 2014 г. $-0,67$, в 2015 г. $-0,45$, в третий год корреляция была недостоверной.

Продуктивность колоса определяется его озерненностью и массой зерновки. Число зерен в колосе в первый и третий год исследова- ния не имело статистически значимых отличий и составило соответственно $31,3 \pm 3,1$ шт. и $30,6 \pm 2,6$ шт. Во второй год отмечали более высокую величину этого показателя, а также широкий ее разброс по сортам - 32,7士4,9 шт. (см. рис. 1). Коэффициент вариации озерненности колоса по годам исследования был стабильным и составил $7 \%$. Существенные отличия по годам исследования наблюдали по массе зерновок $-C V-23 \%$. Самая низкая масса 1000 зерен отмечена в 2014 г. - 26,3 $\pm 3,0$ г, причинами формирования щуплого зерна были пониженный тепловой режим во время вегетации растений и загущенный стеблестой. Более высокой она была в 2015 г. и 2016 г. $39,1 \pm 3,2$ и $35,5 \pm 3,8$ г соответственно.

Урожай сельскохозяйственных культур формируется благодаря фотосинтетической деятельности растений. Ассимилирующие органы пшеницы - это, прежде всего, верхние листья, размеры которых тесно коррелируют с продуктивностью колоса, а также колос, стебли, влагалища листьев, ости. Во второй год исследования площадь флагового листа $32,8 \pm 5,3$ см была выше, чем в первом и третьем годах $-26,1 \pm 3,8$ и $24,6 \pm 3,7$ см соответственно, аналогичная ситуация сложилась и по длине колоса - соответственно $9,0 \pm 0,7 \mathrm{~cm}$, $8,6 \pm 0,6$ см и $8,7 \pm 0,7$ см соответственно. При этом во второй год растения были самыми низкорослыми - $75,3 \pm 6,7 \mathrm{cm,} \mathrm{против}$ $101,4 \pm 9,0$ и $111,8 \pm 9,9$ см в первый и третий год соответственно, с наименьшим числом колосков в колосе - 15,1 1 , 5 шт., $15,8 \pm 1,1$ и $18,0 \pm 1,1$ шт.

В целом в первый год вегетации наблюдали загущенный стеблестой с числом продуктивных побегов в 1,4 и 1,3 раз выше, чем в 2015 и 2016 гг. соответственно. При этом продуктивность колоса была самой низкой за все время экспериментов. Во второй год исследования отмечали самую высокую продуктивность колоса - больше, чем в 2014 и 2016 гг., в 1,6 и 1,2 раза соответственно, а также самую 

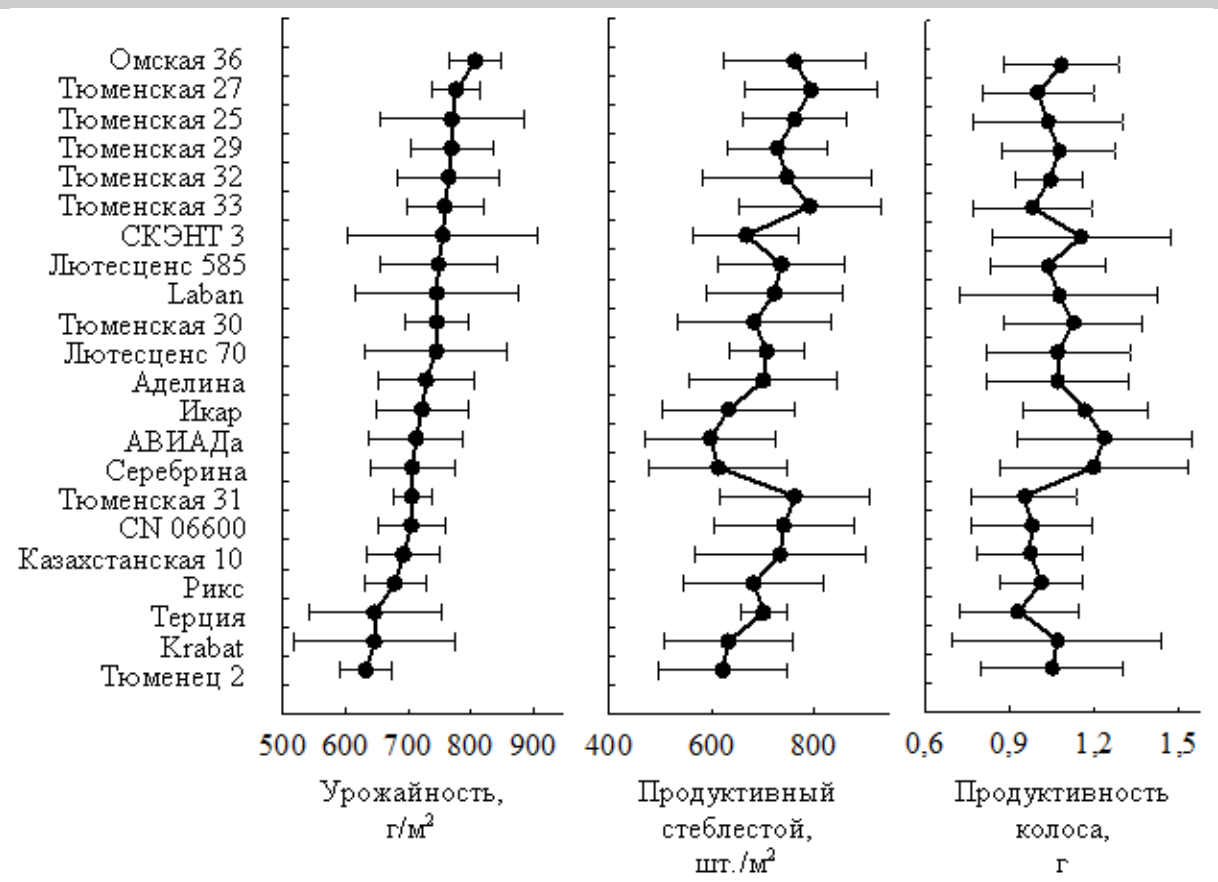

Рис. 2 - Сортовые показатели (M, SD) урожайности, продуктивного стеблестоя и продуктивности колоса

значительную площадь флагового листа, превышавшую величины этого показателя в первый и третий годы в 1,2 и 1,3 раза, растения были ниже, чем в другие годы. Средняя по сортам длина стебля растений пшеницы в 2016 г. превышала величину показателя в 2015 г. в 1,5 раза, в 2014 г. - в 1,1 раза.

Наибольшую урожайность в период исследования обеспечил сорт Омская $36-807 \pm 42$ г/ $\mathrm{M}^{2}$, самую низкую - Тюменец $2-632 \pm 42$ г/ $\mathrm{m}^{2}$, при этом продуктивность колоса у них была одинаковой $-1,1$ г/ ${ }^{2}$, но растения значительно отличались по числу продуктивных побегов $-762 \pm 138$ шт./м и $622 \pm 126$ шт./м ${ }^{2}$ соответственно (рис. 2). В целом урожайность исследованных сортов пшеницы положительно коррелировала с продуктивным стеблестоем $(0,58)$ и не имела статистически значимой связи с продуктивность колоса. У сортов СКЭНТ 3, Laban, Krabat Тюменская 25, Лютесценс 70, Терция отмечено более сильное, относительно других сортов, варьирование урожайности по годам исследования, связанное в основном с более широким разбросом показателей продуктивности колоса. Наименьшее число продуктивных побегов зафиксиро-

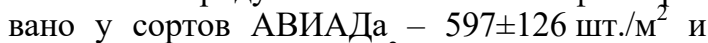
Серебрина $613 \pm 135$ шт./м², при этом у них была самая высокая масса зерна с колоса $1,23 \pm 0,31$ г и 1,20 $\pm 0,33$ г соответственно. Между этими двумя признаками выявлена обратная связь $(-0,60)$. Таким образом, недостаточное число продуктивных побегов компенсировалось более высокой продуктивностью колоса. Сорта с относительно низким продуктивным стеблестоем характеризовались более высокими показателями длины колоса $(-0,46)$, количества колосков $(-0,61)$ и зерен $(-0,60)$, площади флагового листа $(-0,59)$. У сортов Рикс, Авиа- да, Серебрина и Казахстанская 10 отмечены наибольшие длина колоса $(9,6 \ldots 10,4$ см) и площадь флагового листа $\left(31,9 \ldots 33,8 \mathrm{~cm}^{2}\right)$, у сортов Krabat и Laban - число зерен в колосе $(41,2$ и 36,0 шт.), у сортов Омская 36, Тюменская 32, Рикс, Казахстанская 10 - масса 1000 зерен (36,3 ...37,3 г). Выявлена отрицательная корреляция между числом зерен в колосе и массой 1000 зерен $(-0,70)$, то есть относительно низкая озерненность колоса компенсировалась укрупнением зерна.

Коэффициенты вариации (CV) количественных признаков яровой пшеницы по сортам находились на следующих уровнях: урожайность - $6 \%$, продуктивный стеблестой $8 \%$, продуктивность колоса - $7 \%$, число зерен в колосе - $10 \%$, масса 1000 зерен - 9\%.

Выводы. Контрастные по температурному режиму и сумме выпавших осадков метеоусловия в годы исследования привели к существенным различиям в уровне развития основных элементов урожайности. Значительную степень вариации ( $C V$ более 20 \%) по годам наблюдали для числа побегов, массы зерна с колоса, массы 1000 зерен и длины стебля. В наименьшей степени $(C V-2 \ldots 3 \%)$ изменялись длина колоса и число зерен в колосе. Несмотря на значительное варьирование по годам исследования уровней развития отдельных количественных признаков пшеницы, урожайность изменялась в незначительной степени $(C V-7 \%)$, благодаря компенсаторным механизмам, благодаря которым недостаточное развитие одного элемента структуры урожая, приводило к усиленному формированию другого. Средняя урожайность в 2014,

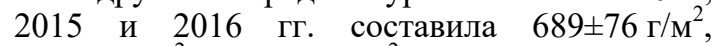
$787 \pm 75$ г $/ \mathrm{M}^{2}$ и $700 \pm 60$ г $/ \mathrm{M}^{2}$ соответственно. Коэффициенты вариации основных элементов 
урожая по исследованным сортам не превышали $10 \%$, а для урожайности он был равен $6 \%$. Результаты анализа сортовых различий хозяйственно-ценных признаков в контраст- ных условиях вегетации могут способствовать более успешному подбору и распространению сортов яровой мягкой пшеницы в сельскохозяйственном производстве.

\title{
Литература
}

1. IPCC, 2013: Climate Change 2013: The Physical Science Basis.URL: https://www.ipcc.ch/report/ar5/wg1/ (дата обращения 26.03.2021)

2. IPCC, 2018: Global Warning of $1,5^{\circ}$ C.URL: https://www.ipcc.ch/sr15/ (дата обращения 26.03.2021)

3. Оценка стратегического прогноза изменений климата Российской Федерации на период до 20102015 гг. и их влияния на отрасли экономики России / Федеральная служба по гидрометеорологии и мониторингу окружающей среды (Росгидромет), Климатический центр Росгидромета. Санкт-Петербург: Д’АРТ: Главная географическая обсерватория им. А.И. Воейкова, 2017. 44 с.

4. IPCC, 2019: Climate Change and Land. URL: https://www.ipcc.ch/srccl/ (дата обращения 26.03.2021)

5. Доклад о климатических рисках на территории Российской Федерации / Е. М. Акентьева, Е. И. Александров, Г. В. Алексеев и др. / под ред. В. М. Катцова. Санкт-Петербург: Главная геофизическая обсерватория им. А.И. Воейкова, 2017. 106 с.

6. Temperature increase reduces global yields of major crops in four independent estimates / C. Zhao, B. Liu, S. Piao, et al. // Proc. Natl. Acad. Sci.2017. Vol. 114. No. 35. P. 9326-9331. doi:10.1073/pnas.1701762114.

7. Similar estimates of temperature impacts on global wheat yield by three independent methods/ Liu B., Asseng S., Müller C., et al. //Nature Clim Change.2016.Vol. 6.P. 1130-1136.doi:10.1038/nclimate3115.

8. Jones N. Redrawing the map: how the world's climate zones are shifting. YaleEnvironment 360. 2018. URL: https://e360.yale.edu/features/redrawing-the-map-how-the-worlds-climate-zones-are-shifting (дата обращения 26.03.2021)

9. Государственному испытанию новых сортов сельскохозяйственных культур по Тюменской области 80 лет / Ю.П.Логинов, А.А.Казак, С.Н. Ященко и др.// Агропродовольственная политика России. 2018. № 5 (77). C. $30-35$.

10. Программа работ комплексного селекционно-семеноводческого центра по растениеводству научноисследовательского института сельского хозяйства Северного Зауралья на период 2011-2030 гг. / под ред. В.В. Новохатина. Тюмень: «Печатник», 2011.98 с.

11. Система адаптивно-ландшафтного земледелия в природно-климатических зонах Тюменской области / Н. В. Абрамов, Ю. А. Акимова, Л. Г. Бакшеев и др. // Тюмень: АО «Тюменский издательский дом», 2019. $472 \mathrm{c}$.

12. Поляков М.В., Белкина Р.И., Шулепова О.В. Яровая пшеница и ячмень в Северном Зауралье: сорта, элементы технологии, урожайность и качество зерна. Тюмень: ФГБОУ ВО ГАУ Северного Зауралья, 2020. $148 \mathrm{c}$.

13. Новохатин В.В. Биоклиматические ресурсы Северного Зауралья // Аграрный вестник Урала. 2015. № 8(138). C. 22-28.

14. Казак А.А., Логинов Ю.П. Сортовые ресурсы яровой мягкой пшеницы Западной Сибири в решении продовольственной безопасности региона // Зерновое хозяйство России. 2016. № 3. С. 44-47.

Сведения об авторах:

Земцова Елена Сергеевна - научный сотрудник, аспирант, e-mail: zemcovaelena@mail.ru

Тобольская комплексная научная станция Уральского отделения РАН, Тобольск, Россия

Тюменский государственный университет, Тюмень, Россия

Нина Анатольевна Боме - доктор сельскохозяйственных наук, зав. кафедрой ботаники, биотехнологии растений и ландшафтной архитектуры ТюмГУ, e-mail: bomena@mail.ru

Тюменский государственный университет, Тюмень, Россия

\section{ANALYSIS OF THE STRUCTURE OF THE SPRING WHEAT CROP IN VARIOUS WEATHER CONDITIONS IN THE TYUMEN REGION \\ E.S. Zemtsova, N.A. Bome}

\begin{abstract}
During the growing seasons of 2014-2016, 22 varieties of spring soft wheat were evaluated according to economically valuable characteristics. The purpose of the work was to determine the features of the formation of the yield of the studied varieties based on the analysis of the variability of the main elements of its structure in the conditions of the taiga agro-climatic zone of Tyumen region. Varieties belonging to two groups of ripeness (medium-early and mediumripe) were evaluated on plots with an accounting area of $1 \mathrm{~m}^{2}$, the repetition of the experiment was 4-fold. The soil is loamy in terms of granulometric composition, the humus content is $4.5 \%, \mathrm{pH}=7.1$. The limiting factor of the wheat harvest in the first year of the study was insufficient heat supply (the average daily air temperature is $1.4{ }^{\circ} \mathrm{C}$ lower than the average long-term value) against the background of a lack of precipitation (62\% relative to the norm), which caused the formation of a puny grain. In the second year, heavy precipitation (155\% of the norm for the growing season) and having a stormy character in July led to the lodging of plants and an increase in the contamination of grain with fungal diseases. In the third year, the high air temperature $\left(3.2^{\circ} \mathrm{C}\right.$ higher than long-term indicators) caused a reduction in the duration of the tillering phase and a decrease in the number of productive shoots. The signs - the number of shoots, the weight of grain from the ear, the weight of 1000 grains and the length of the stem (the coefficients of variation (CV) were $-20 \ldots .22 \%$ ) were subject to a significant degree of variation during the study period, the number of grains in the ear and the length of the ear $(\mathrm{CV}-2 \ldots .3 \%)$ practically did not change. We observed the compensation of some elements of the crop structure by others. Thus, the insufficient number of stems was compensated by an increase in the share of productive stems, a low number of productive shoots - by a higher productivity of the ear, a relatively low water content of the ear - by an increase in the mass of 1000 grains. As a result, the yield level varied slightly over the years of the study (CV-7 \%).
\end{abstract}


Keywords: soft wheat spring (Triticum aestivum L.), variety, structure of crop, weather conditions, Tyumen region.

\section{References}

1. IPCC. 2013: Climate change 2013: the physical science basis. [cited 2021, March 26]. Available from: https:// www.ipcc.ch/report/ar5/wg1/

2. IPCC. 2018: Global warning of 1.5 C. [cited 2021, March 26]. Available from: https://www.ipcc.ch/sr15/

3. Otsenka strategicheskogo prognoza izmenenii klimata Rossiiskoi Federatsii na period do 2010-2015 gg. i ikh vliyaniya na otrasli ekonomiki Rossii. Federal'naya sluzhba po gidrometeorologii i monitoringu okruzhayushchei sredy (Rosgidromet). Klimaticheskii tsentr Rosgidrometa. [Assessment of the strategic forecast of climate change in the Russian Federation for the period up to 2010-2015 and their impact on the sectors of the Russian economy. Federal service for hydrometeorology and environmental monitoring (Roshydromet). Climate center of Roshydromet]. Sankt-Peterburg: D'ART: Glavnaya geograficheskaya observatoriya im. A.I. Voeikova. 2017; 44 p.

4. IPCC. 2019: Climate change and land. [cited 2021, March 26]. Available from: https://www.ipcc.ch/srccl/

5. Akent'eva EM, Aleksandrov EI, Alekseev GV, Kattsova VM. Doklad o klimaticheskikh riskakh na territorii Rossiiskoi Federatsii. [Report on climatic risks on the territory of the Russian Federation]. Sankt-Peterburg: Glavnaya geofizicheskaya observatoriya im. A.I. Voeikova. 2017; 106 p.

6. Zhao C, Liu B, Piao S. [Temperature increase reduces global yields of major crops in four independent estimates]. Proc. Natl. Acad. Sci. 2017; Vol. 114. 35. 9326-9331 p. doi:10.1073/pnas.1701762114.

7. Liu B, Asseng S, Müller C. [Similar estimates of temperature impacts on global wheat yield by three independent methods]. Nature climate change. 2016; Vol. 6. 1130-1136 p. doi:10.1038/nclimate3115.

8. Jones N. Redrawing the map: how the world's climate zones are shifting. [Internet]. Yale environment 360. 2018; [cited 2021, March 26]. Available from:: https://e360.yale.edu/features/redrawing-the-map-how-the-worlds-climate-zonesare-shifting

9. Loginov YuP, Kazak AA, Yashchenko SN. [State testing of new varieties of agricultural crops in Tyumen region is 80 years old]. Agroprodovol'stvennaya politika Rossii. 2018; 5(77). 30-35 p.

10. Novokhatin VV. Programma rabot kompleksnogo selektsionno-semenovodcheskogo tsentra po rastenievodstvu nauchno-issledovatel'skogo instituta sel'skogo khozyaistva Severnogo Zaural'ya na period 2011-2030 gg. [The program of work of the integrated selection and seed center for crop production of the Research Institute of Agriculture of the Northern Trans-Urals for the period 2011-2030]. Tyumen': "Pechatnik". 2011; 98 p.

11. Abramov NV, Akimova YuA, Baksheev LG. Sistema adaptivno-landshaftnogo zemledeliya v prirodnoklimaticheskikh zonakh Tyumenskoi oblasti. [The system of adaptive landscape farming in the natural and climatic zones of Tyumen region]. Tyumen': AO “Tyumenskii izdatel'skii dom”. 2019; $472 \mathrm{p}$.

12. Polyakov MV, Belkina RI, Shulepova OV. Yarovaya pshenitsa i yachmen' v Severnom Zaural'e: sorta, elementy tekhnologii, urozhainost' i kachestvo zerna. [Spring wheat and barley in the Northern Urals: varieties, technology elements, yield and grain quality]. Tyumen': FGBOU VO GAU Severnogo Zaural'ya. 2020; 148 p.

13. Novokhatin VV. [Bioclimatic resources of the Northern Urals]. Agrarnyi vestnik Urala. 2015; 8(138). 22-28 p.

14. Kazak AA, Loginov YuP. [Varietal resources of spring soft wheat in Western Siberia in solving food security of the region]. Zernovoe khozyaistvo Rossii. 2016; 3. 44-47 p.

Authors:

Zemtsova Elena Sergeevna - researcher, post-graduate student, e-mail: zemcovaelena@mail.ru

Tobolsk Complex Scientific Station, Ural Branch of the Russian Academy of Sciences, Tobolsk, Russia

Tyumen State University, Tyumen, Russia.

Nina Anatolyevna Bome - Doctor of Agricultural sciences, Head of Botany, Plant Biotechnology and Landscape Architecture Department, Tyumen State University, e-mail: bomena@mail.ru

Tyumen State University, Tyumen, Russia 